\title{
Identificación de los síntomas del cancro cítrico y Procedimientos de descontaminación ${ }^{1}$
}

Mongi Zekri, Holly Chamberlain, Pete Timmer, Pamela Roberts and Rosa Muchovej ${ }^{2}$

\section{Cancro Cítrico o Cancrosis}

El cancro cítrico, causado por la bacteria patógena Xanthomonas axonopodis pv. citri, es una enfermedad seria de la mayoría de las variedades de cítricos. La enfermedad causa lesiones necróticas en hojas, tallos y frutos (Figura 1 y Figura 2).
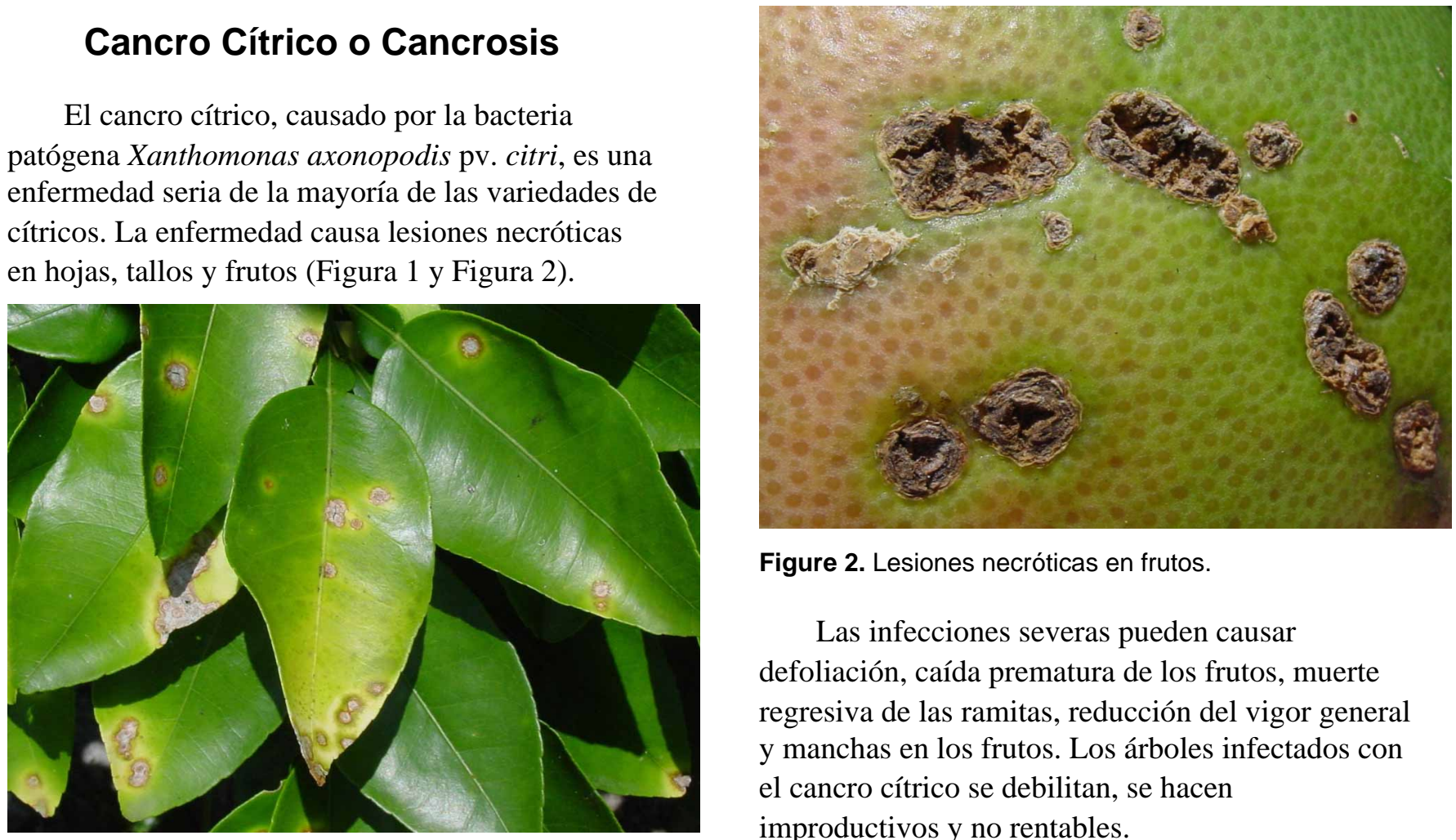

Figure 2. Lesiones necróticas en frutos.

Las infecciones severas pueden causar defoliación, caída prematura de los frutos, muerte regresiva de las ramitas, reducción del vigor general y manchas en los frutos. Los árboles infectados con el cancro cítrico se debilitan, se hacen improductivos y no rentables.

Figure 1. Lesiones necróticas en hojas.

1. Este documento, PP-214-SP, es uno de una serie de publicaciones del Departamento de Plant Pathology, Servicio de Extensión Cooperativa de la Florida, Instituto de Alimentos y Ciencias Agrícolas, Universidad de la Florida. (UF/IUFAS). Fecha de primera publicación: Octubre 2005. Visite nuestro sitio web EDIS en <http://edis.ifas.ufl.edu〉.

2. Mongi Zekri, Citrus Extension Agent IV, Hendry County Extension Office, LaBelle, FL; H. L. Chamberain, coordinator, Educational/Training Programs, Southwest Florida Research and Education Center, Immokalee, FL; L.W. Timmer, professor, Plant Pathology Department, Citrus Research and Education Center, Lake Alfred, FL; P.D. Roberts, assistant professor, Plant Pathology Department, Southwest Florida Research and Education Center, Immokalee, FL; R. M. Muchovej, agronomist, Southwest Florida Research and Education Center, Immokalee, FL; Florida Cooperative Extension Service, Institute of Food and Agricultural Sciences, University of Florida, Gainesville, FL.

The Institute of Food and Agricultural Sciences (IFAS) is an Equal Opportunity Institution authorized to provide research, educational information and other services only to individuals and institutions that function with non-discrimination with respect to race, creed, color, religion, age, disability, sex, sexual orientation, marital status, national origin, political opinions or affiliations. U.S. Department of Agriculture, Cooperative Extension Service, University of Florida, IFAS, Florida A. \& M. University Cooperative Extension Program, and Boards of County Commissioners Cooperating. Larry Arrington, Dean 
El minador de los cítricos (Phyllocnistis citrella) ha aumentado la y susceptibilidad de los cítricos a la cancrosis. Las hojas y tallos dañados por el minador son más sensibles a la infección debido a que las heridas permiten una penetración más fácil de la bacteria a los tejidos (Figura 3 y Figura 4). Cuando las galerías producidas por el minador en las hojas se contaminan con la bacteria, el número y tamaño de las lesiones individuales aumenta grandemente y resulta en una producción enorme de inóculos. Las lesiones en las hojas a veces se caen y dejan agujeros en las mismas.

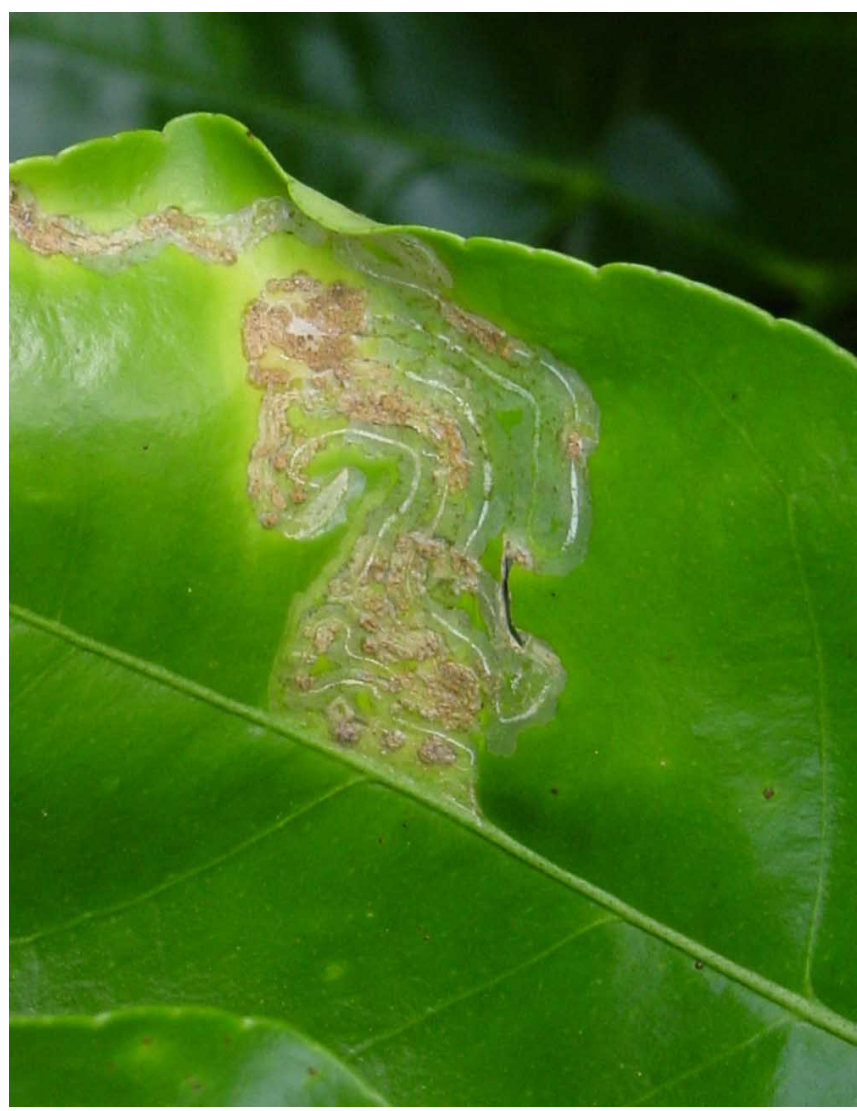

Figure 3. Las hojas y tallos dañados por el minador son más sensibles a la infección debido a que las heridas permiten una penetración más fácil de la bacteria a los tejidos.

SÍNTOMAS EN LAS HOJAS. Las lesiones aparecen en un período de 5-7 días en condiciones óptimas. Los síntomas tempranos lucen como lesiones pequeñas en forma de ampollas elevadas (Figura 5). A medida que las lesiones envejecen se tornan carmelitosas y con margen húmedo rodeado de un anillo o halo amarillo (Figura 6). El centro de la lesión se eleva y es de consistencia similar al

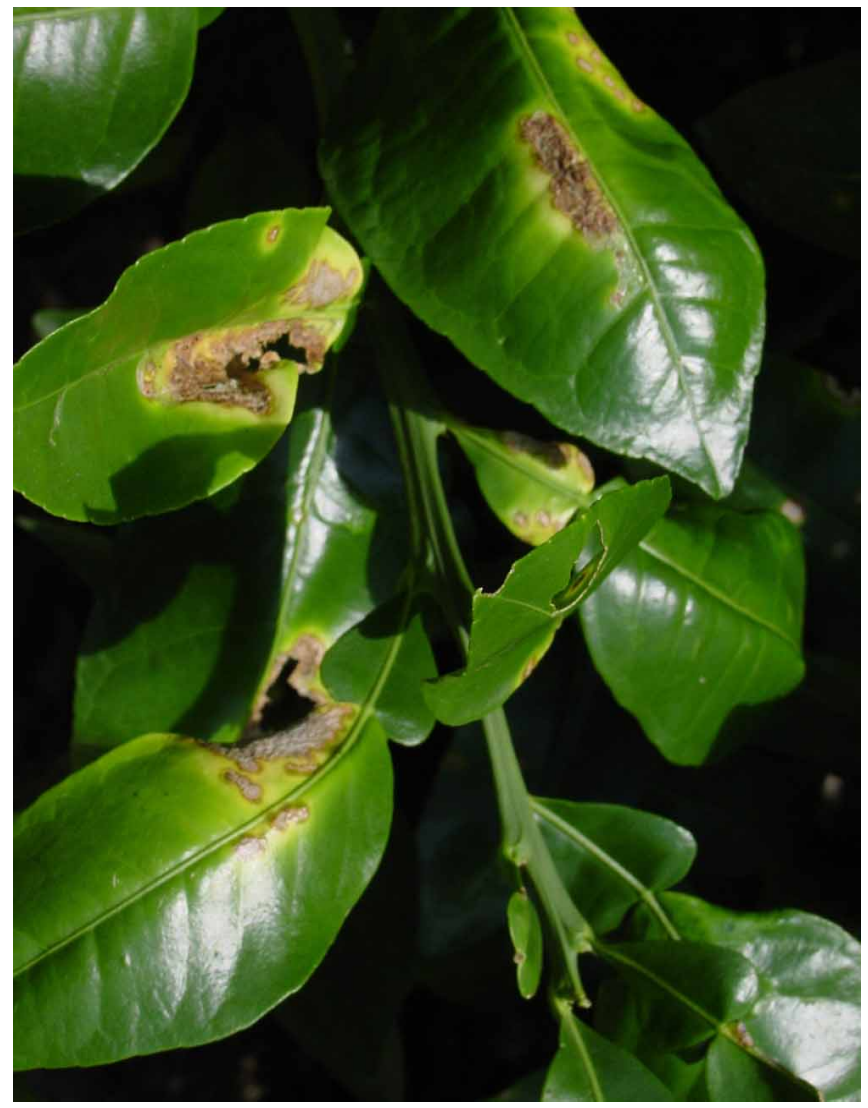

Figure 4. Las hojas y tallos dañados por el minador son más sensibles a la infección debido a que las heridas permiten una penetración más fácil de la bacteria a los tejidos.

corcho. Las lesiones usualmente son visibles en ambas superficies de las hojas.

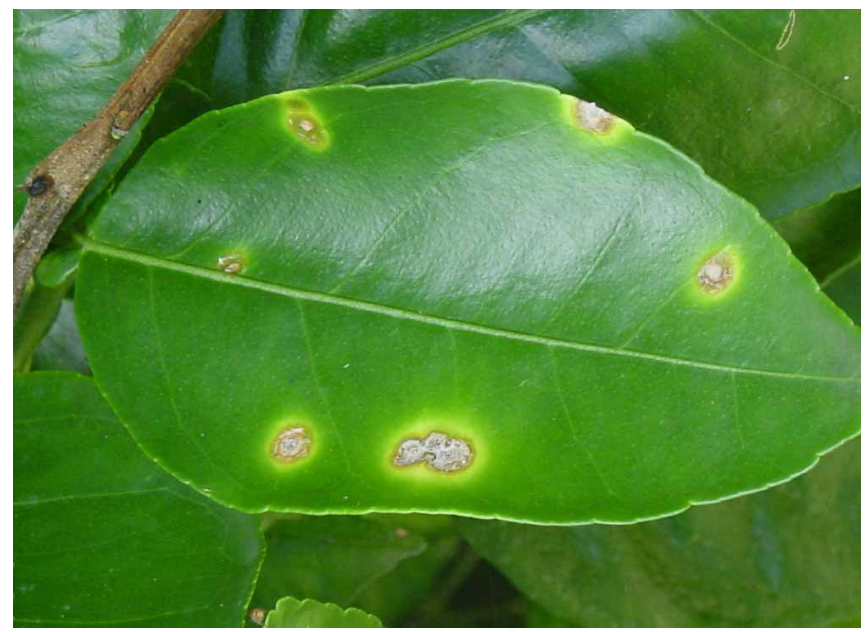

Figure 5. Los síntomas tempranos lucen como lesiones pequeñas en forma de ampollas elevadas.

\section{LESIONES EN TALLOS Y RAMITAS. Las} lesiones en los tallos indican que la infección ha estado presente por un período de tiempo largo. Las 


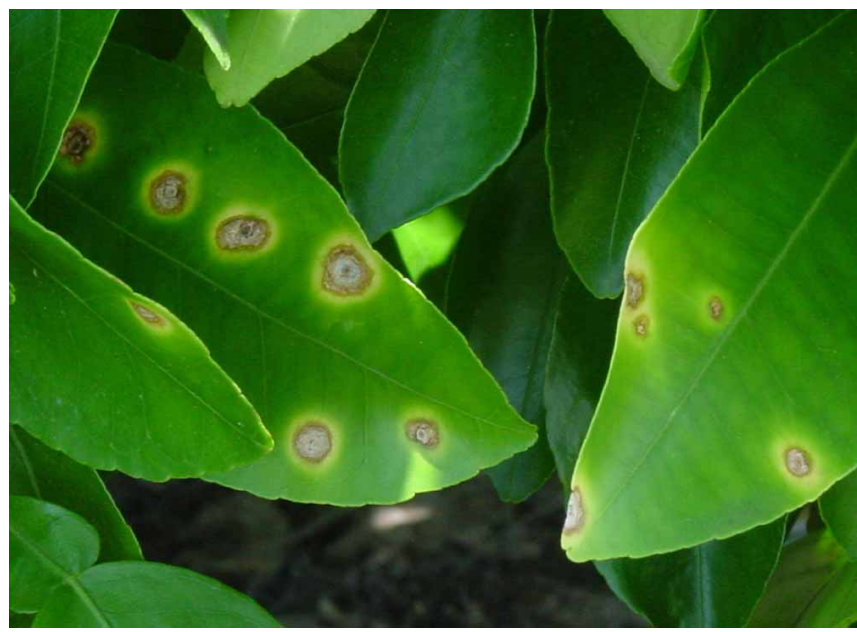

Figure 6. A medida que las lesiones envejecen se tornan carmelitosas y con margen húmedo rodeado de un anillo o halo amarillo.

lesiones en los tallos sirven como reservorios para inóculos persistentes (Figura 7). Los síntomas en ramitas y frutos son similares y consisten de lesiones elevadas de aspecto de corcho, color carmelita oscuro o negra y rodeadas de márgenes húmedos o aceitosos (Figura 8). A medida que las lesiones maduran lucen escamosas o suberosas (Figura 9).

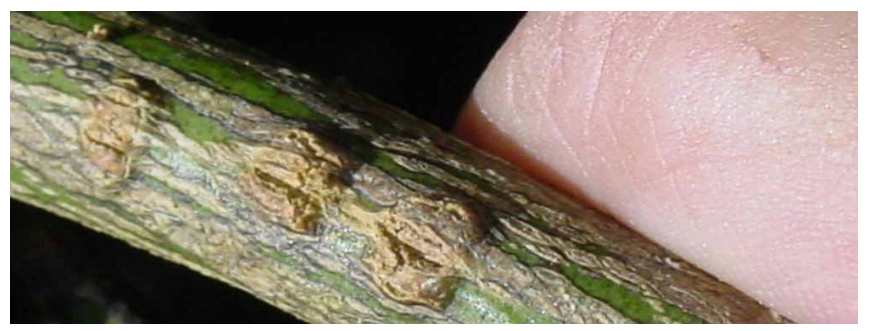

Figure 7. Las lesiones en los tallos sirven como reservorios para inóculos persistentes.

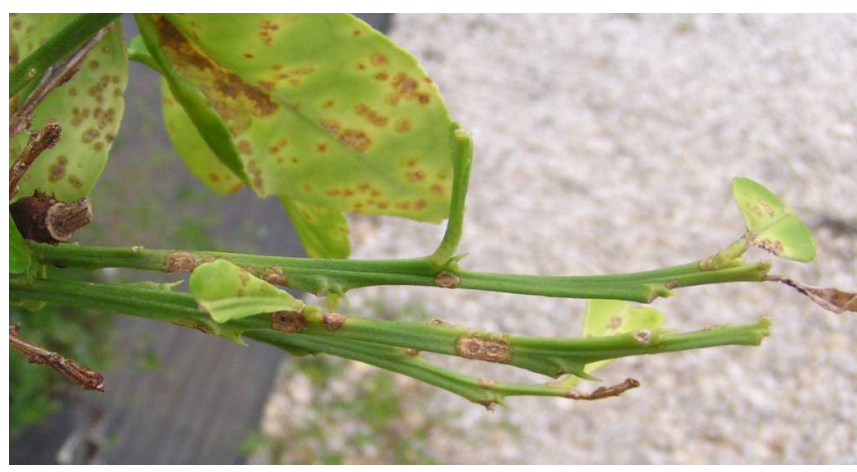

Figure 8. Los síntomas en ramitas consisten de lesiones elevadas de aspecto de corcho, color carmelita oscuro o negra y rodeadas de márgenes húmedos o aceitosos.

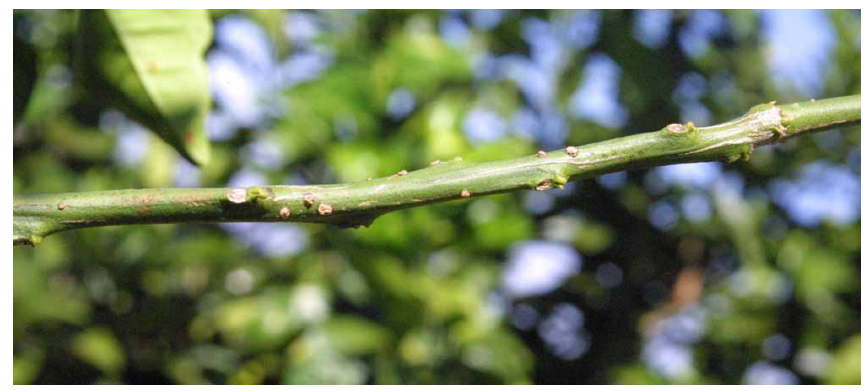

Figure 9. A medida que las lesiones maduran lucen escamosas o suberosas.

LESIONES EN FRUTOS. Son carmelita oscuro a negro, elevadas, a veces con halos amarillos (Figura 10, Figura 11, y Figura 12). Los síntomas pueden variar con el cultivar. Las lesiones causan manchas y caída prematura de frutos lo cual reduce el rendimiento.

El cancro cítrico es altamente contagioso y puede diseminarse rápidamente por las lluvias con vientos, tornados y tormentas tropicales, inundaciones, equipos y el movimiento de las personas dentro de las arboledas.

- El movimiento de árboles infectados o expuestos, posturas, material de propagación y frutos, es el medio primario de diseminación de la cancrosis a largas distancias.

- Ropas contaminadas, herramientas, cortadoras de césped y otros equipos de jardinería, escaleras, macetas y otros artículos asociados con la cosecha y postcosecha son también fuentes potenciales de infección.

\section{Procedimientos de Descontaminacion}

Para prevenir la diseminación de la cancrosis es esencial que los equipos y el personal que trabaja cerca o en contacto con cualquier cítrico sea descontaminado con un producto químico aprobado, tal como amonio cuaternario (Figura 13). 


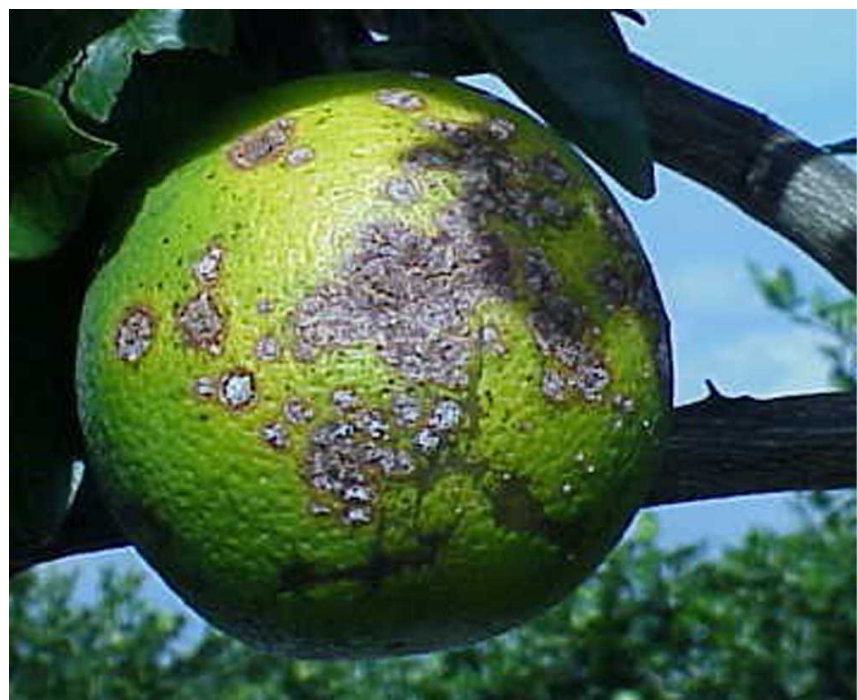

Figure 10. Lesiones en frutos son carmelita oscuro a negro, elevadas, a veces con halos amarillos.

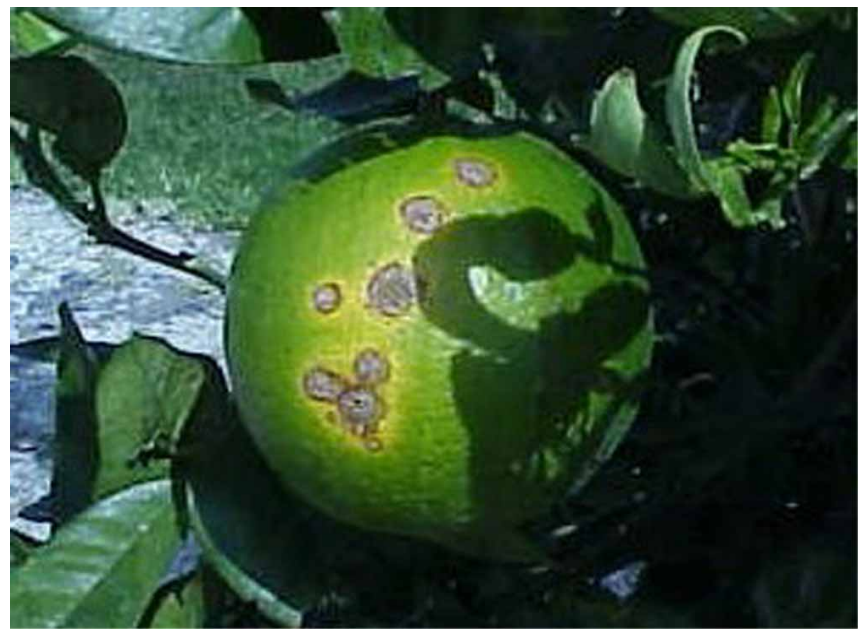

Figure 11. Lesiones en frutos son carmelita oscuro a negro, elevadas, a veces con halos amarillos.

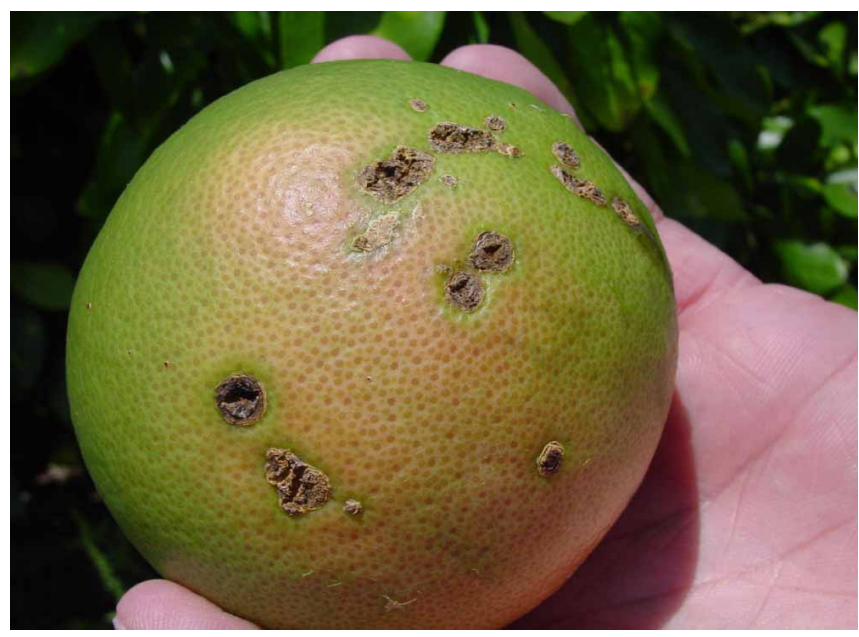

Figure 12. Lesiones en frutos son carmelita oscuro a negro, elevadas, a veces con halos amarillos.

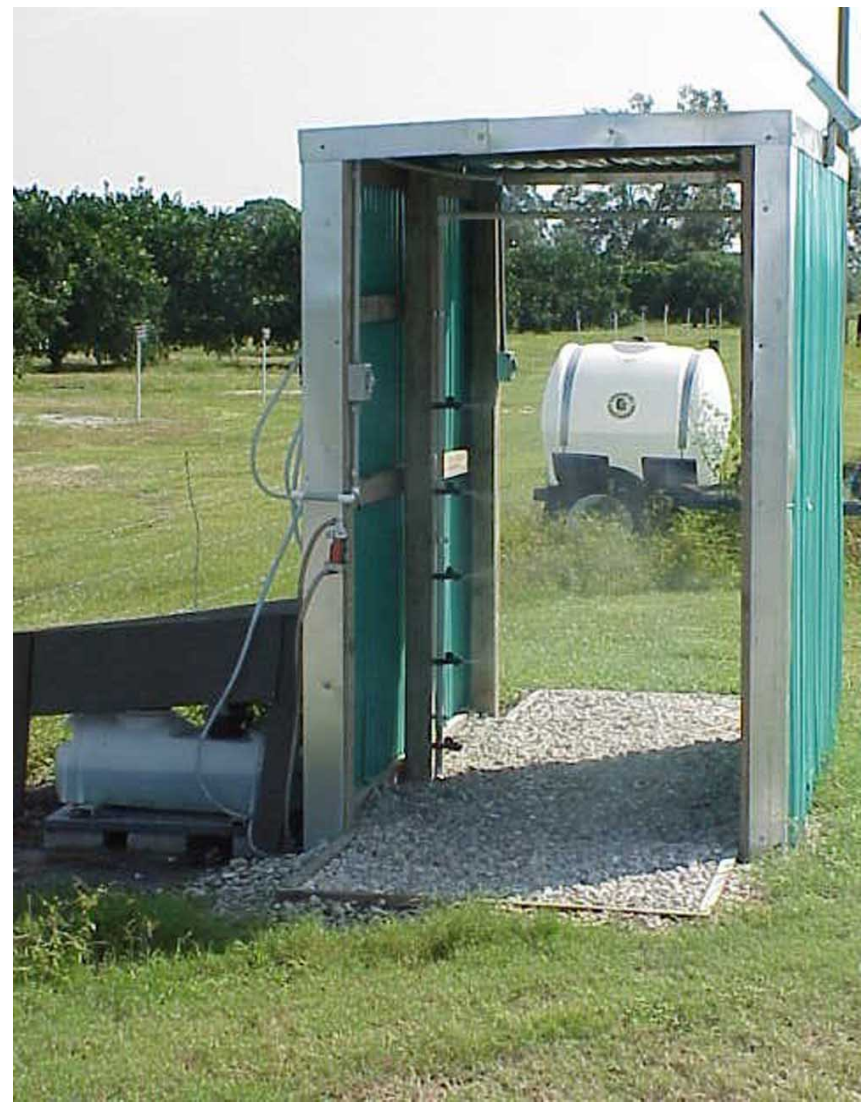

Figure 13. Estación de descontaminacion.

\section{Descontaminacion del Personal}

- Areas Fuera de Cuarentena, el personal tiene que descontaminarse al salir de la arboleda (Figura 14).

- Areas Dentro de la Cuarentena, el personal tiene que descontaminarse al entrar y salir de la arboleda.

\section{- EXCEPCIÓN:}

COSECHEROS/RECOJEDORES tienen que descontaminarse al entrar y salir de una arboleda que esté o no en áreas de cuarentena independientemente de si se ha probado que existe infección.

\section{Descontaminacion de Vehículos y Equipos}

- Areas Fuera de Cuarentena, la ley estatal requiere que todos los vehículos y equipos que entren a las arboledas de cítricos sean descontaminados AL SALIR DE LA ARBOLEDA (Figura 15). 


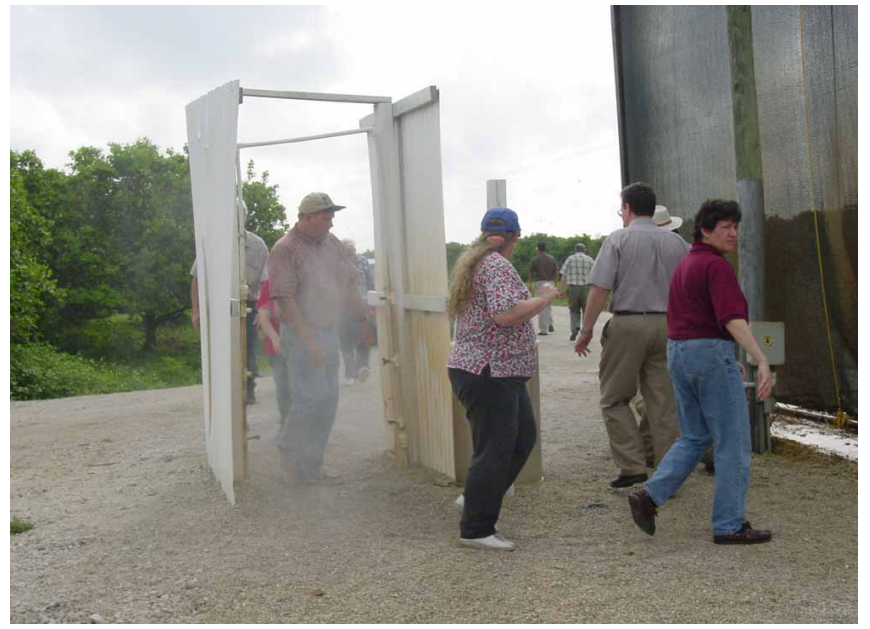

Figure 14. Descontaminacion del personal.

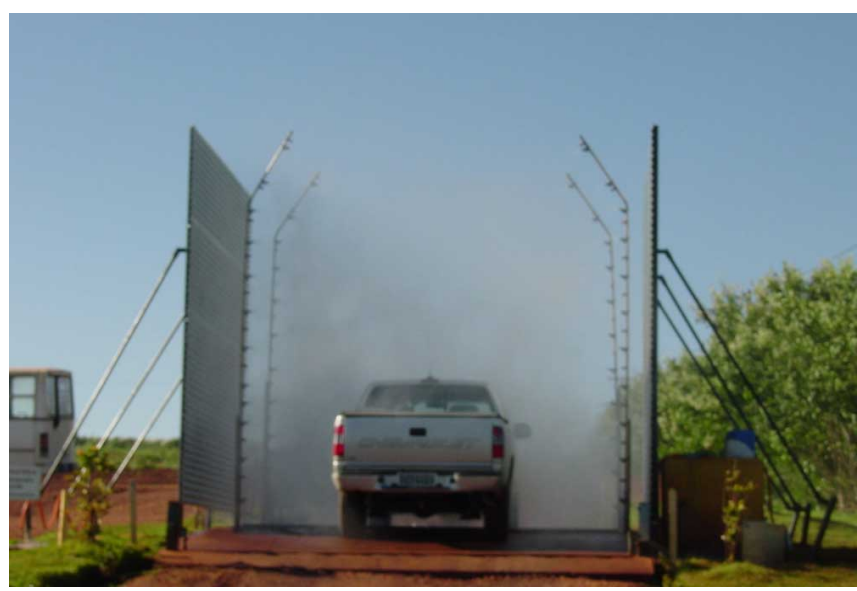

Figure 15. Descontaminacion de vehiculos.

- Areas Dentro de Cuarentena, la ley estatal requiere que todos los vehículos y equipos que entren a las arboledas de cítricos sean descontaminados AL ENTRAR Y SALIR DE LA ARBOLEDA

- Dueños y Gerentes de arboledas pueden requerir descontaminación al entrar arboledas fuera de las áreas de cuarentena.

\section{El mejor manejo de esta enfermedad es: ¡Descontamínese siempre!}

Cualquier persona que sospeche que sus árboles tienen el cancro cítrico debe llamar a Division of Plant Industry al número: 800-282-5153, 800-850-3781 ó 800-293-3101.

- No tome muestras de árboles sospechosos ni las lleve a ningún lugar incluyendo las oficinas de Extensión debido al riesgo de diseminación de la enfermedad.
- No destruya los árboles infectados sin antes reportarlos a los empleados o inspectores federales o estatales.

- Permita que los inspectores entren a su arboleda o patio para evaluar sus cítricos. Permítales eliminar los árboles infectados o expuestos.

\section{Mas Información}

Para mas información sobre la cancrosis, visite las siguientes paginas en la Internet:

\section{Citrus Canker Extension Program}

http://canker.ifas.ufl.edu

\section{Citrus Canker Eradication Program}

http://doacs.state.fl.us/canker

Animal and Plant Health Inspection Service

http://www.aphis.usda.gov/ppq/ep/citruscanker

Crop Alert: A Citrus Canker Fact Sheet for

Homeowners http://edis.ifas.ufl.edu/PP116

\section{Florida Citrus Pest Management} Guide: Citrus Canker

http://edis.ifas.ufl.edu/CG040

\section{Citrus Canker Disease}

http://www.biotech.ufl.edu/PlantContainment/ canker.htm

\section{Plant Containment Facility}

http://www.biotech.ufl.edu/PlantContainment/

\section{Citrus Canker Identification}

http://www.imok.ufl.edu/plant/diseases/ cankerid.htm 